\title{
Camelimonas abortus sp. nov., isolated from placental tissue of cattle
}

\author{
P. Kämpfer, ${ }^{1}$ H. C. Scholz, ${ }^{2}$ N. Lodders, ${ }^{1}$ I. Loncaric, ${ }^{3}$ A. M. Whatmore ${ }^{4}$ \\ and H.J. Busse ${ }^{3}$ \\ ${ }^{1}$ Institut für Angewandte Mikrobiologie, Justus-Liebig-Universität Giessen, D-35392 Giessen, \\ Germany \\ ${ }^{2}$ Bundeswehr Institute of Microbiology, Neuherbergstrasse 11, D-80937 Munich, Germany \\ ${ }^{3}$ Institut für Bakteriologie, Mykologie und Hygiene, Veterinärmedizinische Universität, A-1210 Wien, \\ Austria \\ ${ }^{4}$ Department of Bacteriology, Animal Health \& Veterinary Laboratories Agency, Woodham Lane, \\ Addlestone, Surrey KT15 3NB, UK
}

\begin{abstract}
A Gram-negative, rod-shaped, non-spore-forming bacterium, isolated from placental tissue of a cow, was investigated for its taxonomic position. On the basis of 16S rRNA gene sequence similarities, strain UK34/07-5 ${ }^{\top}$ was shown to belong to the class Alphaproteobacteria, closely related to the type strain of Camelimonas lactis ( $96.0 \%$ sequence similarity). The polyamine pattern showed the major compound spermidine and moderate amounts of putrescine. The major quinone was ubiquinone Q10. The polar lipid profile was composed of the major compounds phosphatidylethanolamine, phosphatidylcholine, phosphatidylglycerol and phosphatidylmonomethylethanolamine and moderate amounts of diphosphatidylglycerol, three unidentified aminolipids and an unidentified phospholipid. The profile of major fatty acids, consisting of $\mathrm{C}_{19: 0}$ cyclo $\omega 8 c$ and $\mathrm{C}_{18: 1} \omega 7 c$, with $\mathrm{C}_{18: 0} 3-\mathrm{OH}$ as the hydroxylated fatty acid, was very similar to that of C. lactis $M 2040^{\top}$. The results of DNA-DNA hybridization and physiological and biochemical tests allowed both genotypic and phenotypic differentiation of the isolate from $\mathrm{C}$. lactis. The relatively low $16 \mathrm{~S}$ rRNA gene sequence similarity of $96.0 \%$ to C. lactis $M 2040^{\top}$ and marked differences in the polar lipid profiles as well as the results of physiological tests and the DNA-DNA hybridization data support the creation of a novel species, for which the name Camelimonas abortus sp. nov. is proposed, with the type strain UK34/07-5 ${ }^{\top}(=\mathrm{CIP}$

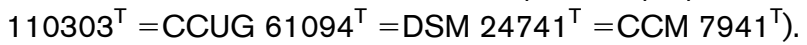

Strain UK34/07-5 $5^{\mathrm{T}}$ was initially cultured on Farrell's medium (Farrell, 1974) from placental tissue following a case of abortion in a Holstein-Frieiaen cow in Derbyshire, UK, in 2007. Farrell's medium was manufactured using a Brucella medium base (CM0169; Oxoid) and a Brucella selective supplement (SR0209E; Oxoid). However, initial identification by classical methods failed. Subsequent sequence analysis of the $16 \mathrm{~S}$ rRNA gene revealed Camelimonas lactis $\mathrm{M} 2040^{\mathrm{T}}$ as the closest phylogenetic neighbour. The genus Camelimonas was recently described by Kämpfer et al. (2010) for a group of Gram-negative, rodshaped, non-spore-forming bacteria, isolated from milk of camels at a camel milk production farm in the United Arab Emirates. To investigate whether strain UK34/07- $5^{\mathrm{T}}$ is indeed

Abbreviations: oNP, o-nitrophenyl; pNA, $p$-nitroanilide; pNP, $p$-nitrophenyl. The GenBank/EMBL/DDBJ accession number for the 16S rRNA gene sequence of strain UK34/07-5 is FR851926. a member of the genus Camelimonas, the strain was studied by following a polyphasic approach.

Strain UK34/07-5 ${ }^{\mathrm{T}}$ showed a beige-coloured colony on nutrient agar (Oxoid) at $37{ }^{\circ} \mathrm{C}$. Subcultivation for further analyses was done on tryptone soy agar (TSA; Oxoid) at $28{ }^{\circ} \mathrm{C}$ for $48 \mathrm{~h}$. Gram-staining was performed as reported previously by Gerhardt et al. (1994) and the staining result, as well as the cell morphology, were observed with a Zeiss light microscope at $\times 1000$. Cells for these studies were grown for 3 days at $28{ }^{\circ} \mathrm{C}$ on TSA. The $16 \mathrm{~S}$ rRNA gene was sequenced as reported by Kämpfer et al. (2003). A 'phylogenetic' analysis was performed using the ARB software package (Ludwig et al., 2004) and the corresponding SILVA SSURef 100 database (release August 2009; Pruesse et al., 2007) as well as with the software package MEGA version 4 (Tamura et al., 2007). Multiple alignment of the data was performed by using CLUSTAL_X (Thompson et al., 1997). Pairwise distances were calculated and clustering with the neighbourjoining method was performed by using bootstrap values 


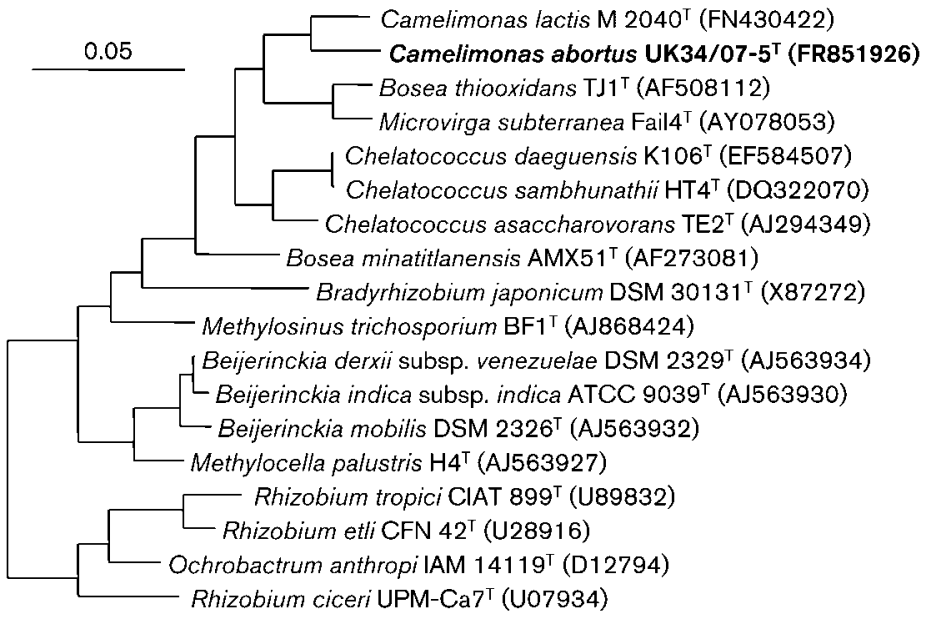

Fig. 1. Phylogenetic analysis based on $16 \mathrm{~S}$ rRNA gene sequences of strain UK34/07-5 and selected type strains of the class Alphaproteobacteria. Accession numbers are shown in parentheses. The phylogenetic tree was calculated with the maximum-likelihood method without filters. Bar, 0.05 substitutions per nucleotide position. based on 1000 replications. A maximum-likelihood tree was reconstructed with fastDNAmL (Olsen et al., 1994) without filters.

These calculations showed that the 16S rRNA gene sequence of isolate UK34/07-5 $5^{\mathrm{T}}$ showed the highest similarity to that of C. lactis M $2040^{\mathrm{T}}$ (96.0\%). Similarities to the type strains of other related genera, like Chelatococcus, Bosea and Microvirga, were below $96 \%$. A maximum-likelihood tree is shown in Fig. 1. The branching pattern was confirmed by maximum-parsimony and neighbour-joining analyses (not shown).

For quinone, polar lipid and polyamine cell-wall diamino acid analyses, cells were grown on $3.3 \times$ PYE medium $(1.0 \%$ peptone from casein, $1.0 \%$ yeast extract, $\mathrm{pH} 7.2)$ for $72 \mathrm{~h}$ at $28{ }^{\circ} \mathrm{C}$. Polar lipids and quinones were extracted and analysed as described previously (Tindall, 1990a, b; Altenburger et al., 1996). Polyamines were extracted and analysed as described by Busse \& Auling (1988). HPLC analyses were carried out using the equipment described by Stolz et al. (2007). The polar lipid profile of UK34/07-5 (Fig. 2) consisted of the major compounds phosphatidylethanolamine, phosphatidylmonomethylethanolamine, phosphatidylglycerol and phosphatidylcholine and moderate amounts of diphosphatidylglycerol, three unidentified aminolipids and an unidentified phospholipid. The quinone system was ubiquinone Q-10 (99\%) with traces of Q-9 and Q-11 (both less than 1\%). The polyamine pattern consisted of spermidine $[49.4 \mu \mathrm{mol} \text { (g dry weight })^{-1}$, putrescine $\left[11.5 \mu \mathrm{mol}\right.$ (g dry weight) $\left.{ }^{-1}\right]$, spermine $[1.0 \mu \mathrm{mol}$ (g dry weight $\left.)^{-1}\right]$ and traces of cadaverine $[<0.1 \mu \mathrm{mol}$ (g dry weight $\left.)^{-1}\right]$. The quinone system and polyamine pattern are in excellent agreement with those of $C$. lactis (Kämpfer et al., 2010). Also, the polar lipid profile of isolate UK34/07-5 showed most of the lipids reported for C. lactis, but the presence of an unidentified phospholipid and absence of an unidentified glycolipid distinguish isolate UK34/07-5 ${ }^{\mathrm{T}}$ from C. lactis.

The fatty acid profile of the strain is shown in Table 1 , together with that of C. lactis $\mathrm{M} 2040^{\mathrm{T}}$. No pronounced differences in fatty acid profiles were found between the strains; however, slight differences could be observed. The major fatty acids were $\mathrm{C}_{19: 0}$ cyclo $\omega 8 c, \mathrm{C}_{18: 1} \omega 7 c, \mathrm{C}_{16: 0}$ and $\mathrm{C}_{18: 0} 3-\mathrm{OH}$ as the hydroxylated fatty acid. The profile was very similar to that reported for C. lactis $\mathrm{M} 2040^{\mathrm{T}}$ (Kämpfer et al., 2010).

The results of the biochemical and physiological characterization are given in the species description and in Table 2 (differential characters), obtained using methods described previously (Kämpfer et al., 1991). The presence of urease was determined as recommended by the manufacturer (Merck; cat. no. 1.08492).

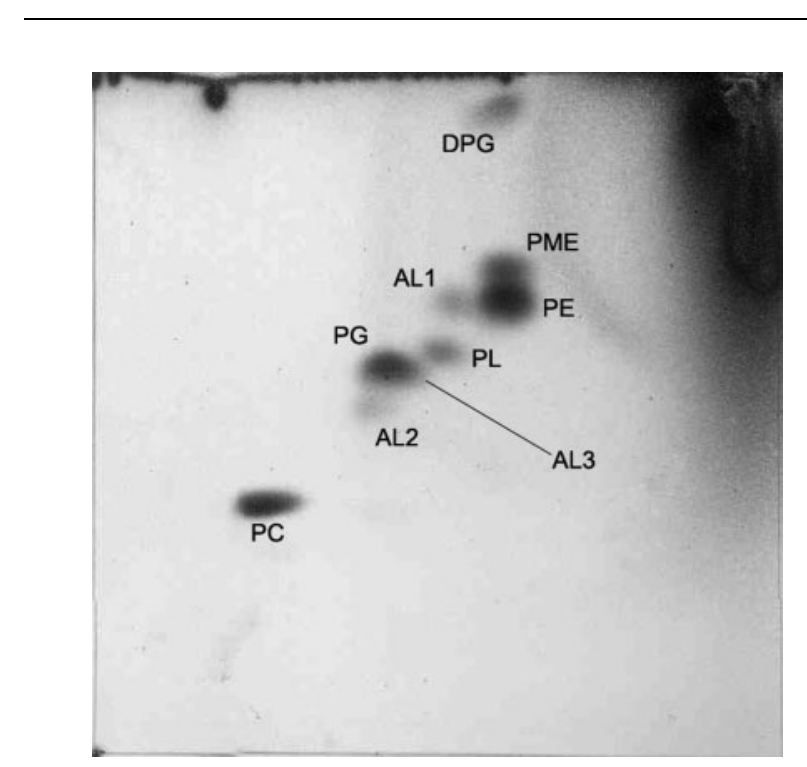

Fig. 2. Polar lipid profile of UK34/07-5 ${ }^{\top}$ after two-dimensional TLC and detection with molybdatophosphoric acid. DPG, Diphosphatidylglycerol; PC, phosphatidylcholine; PE, phosphatidylethanolamine; PG, phosphatidylglycerol; PME, phosphatidylmonomethylethanolamine; $A L 1-3$, unidentified aminolipids; PL, unidentified phospholipid. 
Table 1. Cellular fatty acid contents of strain UK34/07-5 and C. lactis M $2040^{\top}$

Values are percentages of total fatty acids. The fatty acid pattern for strain M $2040^{\mathrm{T}}$ was taken from Kämpfer et al. (2010), but was generated using the same method, as described by Kämpfer \& Kroppenstedt (1996) using an HP gas chromatograph HP 6890 with Sherlock MIDI software version 2.11 and the TSBA peak-naming table version 4.1. - , Not detected.

\begin{tabular}{|c|c|c|}
\hline Fatty acid & Strain UK34/07-5 ${ }^{\mathrm{T}}$ & C. lactis M $2040^{\mathrm{T}}$ \\
\hline Unknown 14.959 & - & 0.8 \\
\hline Summed feature $2^{*}$ & 4.8 & 4.6 \\
\hline Summed feature $3^{*}$ & - & 0.6 \\
\hline $\mathrm{C}_{16: 0}$ & 1.8 & 7.9 \\
\hline $\mathrm{C}_{17: 1} \omega 8 c$ & - & 0.8 \\
\hline $\mathrm{C}_{18: 1} \omega 7 c$ & 27.2 & 11.5 \\
\hline $\mathrm{C}_{18: 0}$ & 5.9 & 1.3 \\
\hline $\mathrm{C}_{19: 0}$ cyclo $\omega 8 \mathrm{c}$ & 52.5 & 67.3 \\
\hline 11-Methyl $C_{18: 1} \omega 7 c$ & 2.6 & 1.4 \\
\hline 10-Methyl $C_{19: 0}$ & - & 1.0 \\
\hline $\mathrm{C}_{18: 0} 3-\mathrm{OH}$ & 3.3 & 1.7 \\
\hline $\mathrm{C}_{20: 2} \omega 6,9 c$ & 1.9 & 1.0 \\
\hline
\end{tabular}

* Summed features are groups of two or three fatty acids that cannot be separated using the MIDI System. Summed feature 2 contained iso- $\mathrm{C}_{16: 1}$ and/or $\mathrm{C}_{14: 0} 3-\mathrm{OH}$; summed feature 3 contained $\mathrm{C}_{16: 1} \omega 7 c$ and/or iso- $\mathrm{C}_{15: 0} 2-\mathrm{OH}$.

DNA-DNA hybridization experiments with C. lactis M $2040^{\mathrm{T}}$ were performed with the method reported by Ziemke et al. (1998). This investigation resulted in DNADNA relatedness values of 18.0 and $13.6 \%$ (reciprocal analysis).

Phylogenetic analysis and $16 \mathrm{~S}$ rRNA gene sequence similarity suggested that isolate UK34/07-5 $5^{\mathrm{T}}$ is a representative of a novel species of the genus Camelimonas, and results from DNA-DNA hybridizations confirmed its status as a member of a novel species. Isolate UK34/07-5 $5^{\mathrm{T}}$ exhibited several physiological traits and a polar lipid profile that were different from those of $C$. lactis. Hence, we propose a novel species for isolate UK34/07-5 ${ }^{\mathrm{T}}$, Camelimonas abortus sp. nov.

\section{Description of Camelimonas abortus sp. nov.}

Camelimonas abortus (a.bor'tus. L. gen. n. abortus of a miscarriage, an abortion, referring to the isolation of the type strain from the placental tissue of a cow following a case of abortion).

Cells are non-motile, non-spore-forming rods (approx. $2 \mu \mathrm{m}$ long and $1 \mu \mathrm{m}$ wide). Gram-stain-negative, oxidaseand catalase-positive, showing an oxidative metabolism. Good growth occurs on R2A agar, TSA, 3.3 $\times$ PYE agar and nutrient agar but not on MacConkey agar at $25-30{ }^{\circ} \mathrm{C}$. Beige-coloured, translucent and shiny colonies with entire edges are formed within $24 \mathrm{~h}$, with a diameter of approx. $2 \mathrm{~mm}$. Predominant compound in the polyamine pattern is
Table 2. Distinguishing characteristics of strain UK34/07-5 and C. lactis M $2040^{\top}$

All data were obtained in this study. Both strains were positive for the utilization of D-glucose, acetate, propionate, adipate, suberate, azelate, glutarate, DL-3-hydroxybutyrate, oxoglutarate and L-aspartate. Both strains were negative for the utilization of $N$-acetyl-D-galactosamine, $\mathrm{N}$-acetyl-D-glucosamine, L-arabinose, $p$-arbutin, cellobiose, $\mathrm{D}$-fructose, D-galactose, D-gluconate, D-mannose, maltose, melibiose, L-rhamnose, D-ribose, salicin, sucrose, D-xylose, D-adonitol, myo-inositol, maltitol, D-mannitol, D-sorbitol, putrescine, cis- and trans-aconitate, L-malate, pyruvate, $\beta$-alanine, D-histidine, L-leucine, L-ornithine, L-phenylalanine, L-proline, L-serine, L-tryptophan, 3-hydroxybenzoate, 4-hydroxybenzoate and phenylacetate. Both strains hydrolysed aesculin, L-alanine pNA, bis-pNP phosphate, pNP phenylphosphonate and L-proline pNA. Neither strain hydrolysed oNP $\beta$-D-galactopyranoside, pNP $\beta$-D-glucuronide, pNP $\alpha$-D-glucopyranoside, $\mathrm{pNP} \beta$-Dglucopyranoside, pNP $\beta$-D-xyloside, $p$-phosphorylcholine or Lglutamate- $\gamma$-3-carboxy pNA.

\begin{tabular}{|lcc|}
\hline Characteristic & Strain UK34/07-5 & C. lactis $^{\mathbf{M}}$ 2040 $^{\mathbf{T}}$ \\
\hline Growth on MacConkey & - & + \\
agar & & \\
Utilization of: & & - \\
Trehalose & + & + \\
4-Aminobutyrate & - & + \\
Citrate & - & + \\
Fumarate & - & + \\
Itaconate & - & + \\
DL-Lactate & - & + \\
Mesaconate & - & + \\
L-Alanine & - & \\
Presence of: & & - \\
Unidentified glycolipid & - & \\
Unidentified & + & \\
phospholipid & & \\
\end{tabular}

spermidine and putrescine is found in moderate amounts. The quinone system is ubiquinone Q-10. The polar lipid profile is composed of the major compounds phosphatidylethanolamine, phosphatidylmonomethylethanolamine, phosphatidylglycerol and phosphatidylcholine and moderate amounts of diphosphatidylglycerol, three unidentified aminolipids and an unidentified phospholipid. The major fatty acids are $\mathrm{C}_{19: 0}$ cyclo $\omega 8 c, \mathrm{C}_{18: 1} \omega 7 c$ and $\mathrm{C}_{16: 0}$ and $\mathrm{C}_{18: 0}$ $3-\mathrm{OH}$ as hydroxylated fatty acid. Utilizes the following carbon sources: D-glucose, trehalose, acetate, propionate, adipate, suberate, azelate, glutarate, DL-3-hydroxybutyrate, oxoglutarate and L-aspartate. Does not utilize $N$ acetyl-D-galactosamine, $\mathrm{N}$-acetyl-D-glucosamine, L-arabinose, p-arbutin, cellobiose, D-fructose, D-galactose, D-gluconate, D-mannose, maltose, melibiose, L-rhamnose, D-ribose, salicin, sucrose, D-xylose, D-adonitol, myo-inositol, maltitol, D-mannitol, D-sorbitol, putrescine, cis- or trans-aconitate, citrate, fumarate, DL-lactate, L-malate, itaconate, mesaconate, pyruvate, $\mathrm{L}$ - or $\beta$-alanine, $\mathrm{D}$-histidine, $\mathrm{L}$-leucine, $\mathrm{L}$-ornithine, L-phenylalanine, L-proline, L-serine, L-tryptophan, 3-hydroxybenzoate, 4-hydroxybenzoate or phenylacetate. 
Hydrolyses aesculin, L-alanine $p$-nitroanilide (pNA), bis-pnitrophenyl (bis-pNP) phosphate, pNP phenylphosphonate and L-proline pNA and does not hydrolyse $o$-nitrophenyl (oNP) $\beta$-D-galactopyranoside, $\mathrm{pNP} \beta$-D-glucuronide, $\mathrm{pNP} \alpha$ D-glucopyranoside, pNP $\beta$-D-glucopyranoside, pNP $\beta$-Dxyloside, $p$-phosphorylcholine or L-glutamate- $\gamma$-3-carboxy pNA. Results of carbon source utilization tests that differentiate the Camelimonas species are indicated in Table 2.

The type strain, UK34/07-5 $5^{\mathrm{T}}\left(=\mathrm{CIP} 110303^{\mathrm{T}}=\right.$ CCUG $61094^{\mathrm{T}}=$ DSM $24741^{\mathrm{T}}=$ CCM $\left.7941^{\mathrm{T}}\right)$, was isolated from placental tissue following a case of abortion in a HolsteinFriesian cow in Derbyshire, UK, in 2007.

\section{Acknowledgements}

We thank Dr J. Euzéby for his nomenclatural advice.

\section{References}

Altenburger, P., Kämpfer, P., Makristathis, A., Lubitz, W. \& Busse, H.-J. (1996). Classification of bacteria isolated from a medieval wall painting. J Biotechnol 47, 39-52.

Busse, H.-J. \& Auling, G. (1988). Polyamine pattern as a chemotaxonomic marker within the Proteobacteria. Syst Appl Microbiol 11, 1-8.

Farrell, I. D. (1974). The development of a new selective medium for the isolation of Brucella abortus from contaminated sources. Res Vet Sci 16, 280-286.

Gerhardt, P., Murray, R. G. E., Wood, W. A. \& Krieg, N. R. (editors) (1994). Methods for General and Molecular Bacteriology. Washington, DC: American Society for Microbiology.

Kämpfer, P. \& Kroppenstedt, R. M. (1996). Numerical analysis of fatty acid patterns of coryneform bacteria and related taxa. Can $J$ Microbiol 42, 989-1005.

Kämpfer, P., Steiof, M. \& Dott, W. (1991). Microbiological characterisation of a fuel-oil contaminated site including numerical identification of heterotrophic water and soil bacteria. Microb Ecol 21, 227-251.

Kämpfer, P., Dreyer, U., Neef, A., Dott, W. \& Busse, H.-J. (2003). Chryseobacterium defluvii sp. nov., isolated from wastewater. Int J Syst Evol Microbiol 53, 93-97.

Kämpfer, P., Scholz, H. C., Langer, S., Wernery, U., Wernery, R., Johnson, B., Joseph, M., Lodders, N. \& Busse, H.-J. (2010). Camelimonas lactis gen. nov., sp. nov., isolated from the milk of camels. Int J Syst Evol Microbiol 60, 2382-2386.

Ludwig, W., Strunk, O., Westram, R., Richter, L., Meier, H., Yadhukumar, Buchner, A., Lai, T., Steppi, S. \& other authors (2004). ARB: a software environment for sequence data. Nucleic Acids Res 32, 1363-1371.

Olsen, G. J., Matsuda, H., Hagström, R. \& Overbeek, R. (1994). fastDNAmL: a tool for construction of phylogenetic trees of DNA sequences using maximum likelihood. Comput Appl Biosci 10, 4148.

Pruesse, E., Quast, C., Knittel, K., Fuchs, B. M., Ludwig, W., Peplies, J. \& Glöckner, F. O. (2007). SILVA: a comprehensive online resource for quality checked and aligned ribosomal RNA sequence data compatible with ARB. Nucleic Acids Res 35, 7188-7196.

Stolz, A., Busse, H.-J. \& Kämpfer, P. (2007). Pseudomonas knackmussii sp. nov. Int J Syst Evol Microbiol 57, 572-576.

Tamura, K., Dudley, J., Nei, M. \& Kumar, S. (2007). MEGA4: molecular evolutionary genetics analysis (MEGA) software version 4.0. Mol Biol Evol 24, 1596-1599.

Thompson, J. D., Gibson, T. J., Plewniak, F., Jeanmougin, F. \& Higgins, D. G. (1997). The CLUSTAL_X windows interface: flexible strategies for multiple sequence alignment aided by quality analysis tools. Nucleic Acids Res 25, 4876-4882.

Tindall, B. J. (1990a). A comparative study of the lipid composition of Halobacterium saccharovorum from various sources. Syst Appl Microbiol 13, 128-130.

Tindall, B. J. (1990b). Lipid composition of Halobacterium lacusprofundi. FEMS Microbiol Lett 66, 199-202.

Ziemke, F., Höfle, M. G., Lalucat, J. \& Rosselló-Mora, R. (1998). Reclassification of Shewanella putrefaciens Owen's genomic group II as Shewanella baltica sp. nov. Int J Syst Bacteriol 48, 179-186. 